\title{
Carl Bovill \\ Fractal Geometry in Architecture and Design \\ Boston: Birkhauser Verlag A.G., 1996
}

Reviewed by Leonard K. Eaton

For hundreds of years architects have used Euclidean geometry in graphic descriptions of their structures. Now Carl Bovill, Associate Professor of Architecture at the University of Maryland, has come forward with a book which claims that architecture and design can benefit from the employment of fractal geometry, a relatively new (1977) mathematical tool. The volume is part of the Design Science Collection, a series edited by Arthur L. Loeb of the Department of Visual and Environmental Studies at Harvard. Loeb is a polymath, a chemical physicist and professional musician. His intellectual interests range over an astonishing number of fields. The term "design science" was coined by Buckminster Fuller. It connotes the employment of scientific and mathematical methods in artistic problems. So it is not hard to see how Bovill's book fits into the series.

The author begins with a few remarks on the nature of symmetry in mathematics and proceeds to definitions: "Fractal geometry is the study of mathematical shapes that display a cascade of never-ending, self-similar, meandering detail as one observes them more closely. The fractal dimension is a mathematical measure of meandering of the texture displayed" (p.3). From this point he moves into a brief treatment of set theory (a bow here to Georg Cantor) and then to an encounter with a few basic fractal constructs such as the Sierpinski gasket and the Koch curve. He does not go through the conventional derivation of the Hausdorff-Besicovitch dimension but simply states it as a power law. I omit his equations.

The familiar problem of the length of the coastline of England is introduced. So far nothing new. What is new and exciting for its application to architecture is the box-counting dimension. This procedure is a systematic extension of the measured and covering dimensions. It is a novel method for determining the range of scale over which self-similarity is present.

For architects, the most interesting sections of the book are probably those in which he applies this method to familiar works of twentieth-century architecture such as the Robie House and Unity Temple. With these buildings Bovill provides diagrams and equations which allow the calculation of the progression of detail from large to small. He correctly notes that the existence of this progression has been previously observed in Wright's work but the quantification is certainly new. The author notes Wright's insistence on natural forms as a 
source of inspiration, but remarks that Wright "...is not clear about how natural inspiration is translated into built form" (p. 127). Professor Bovill should read Wright's 1912 essay on "The Japanese Print". While it is true that Wright's writings tended to "drift around" the concept of organic architecture, he probably came closer in that essay than anywhere else.There is an interesting comparison with the work of Le Corbusier, which indicates less of a progression of detail than with Wright. Bovill is surely correct in noting that Wright's organic architecture called for materials to be used in a way that “...captured nature's complexity. Le Corbusier's purism called for materials to be used in a more industrial way, always looking for efficiency and purity of use" (p. 143). In the next paragraph, however, the author observes that, "The different methods of Frank Lloyd Wright and Le Corbusier produce divergent results even thought they both start with similar materials and similar programs (italics mine). To this last statement I would take the sharpest possible exception. The program of Mr. Robie, who was a bicycle manufacturer in Chicago, and that of Gertrude Stein's brother, with his great collection of paintings by Matisse, had nothing in common.

Notwithstanding the strictures in the foregoing paragraph, this is a valuable book for anyone interested in the analysis of historic architecture. Benoit Mandelbrot himself believed that Beaux Arts buildings had more fractal quality than the severe style of modern architecture represented by Mies Van der Rohe and his school. Bovill confirms the perception of the master and extends it to modern works in the organic tradition such as Reimo Pietiläs' Dipoli Building at Otaniemi and Alvar Aalto's Cultural Center at Wolfsburg. Despite its blemishes, this volume will convince the mathematically minded architect that fractal geometry is a valuable tool for the analysis of a large category of modern buildings. Whether or not it will ever be a useful discipline in the conventional design studio is another matter. "Architectural forms," the author admits, "are man-made and thus very much based on Euclidean geometry" (p. 115). Because carpenters like to build boxes and because the typical fractal form is expensive, we will have to rely on Euclid for most of what is built. But for the understanding of architecture in the organic tradition, fractal geometry offers a most promising approach. This volume is a good treatment of the subject.

\section{For further reading}

Benoit Mandelbrot, The Fractal Geometry of Nature (New York: W.F. Freeman, 1983)

Frank Lloyd Wright, Collected Writings 1894-1930 (New York: Rizzoli, 1992).

\section{The reviewer}

Leonard K. Eaton is Emil Lorch Professor of Architecture Emeritus, the University of Michigan, where he taught architectural history from 1950 to 1988 . He has also taught at Wayne State University, Michigan State University, and the University of Victoria (British Columbia). In 1985 he was Margan Professor at the University of Louisville. He took his B.A. with highest honors at Williams College in 1943, and after war service with the 10th Mountain Division, received an M.A. and Ph.D. from Harvard University. His publications include: Landscape Artist in America: the Life and Work of Jens Jensen (1964); Two Chicago Architects and their Clients (1969); American Architecture Comes of Age (1972); Gateway Cities and Other Essays (1989). He is best known for his work on Frank Lloyd Wright, and is currently studying the anticipation of fractal geometry in the late buildings by that architect. 